\title{
A comparison of residual stresses in multi pass narrow gap laser welds and gas-tungsten arc welds in AISI 316L stainless steel
}

\author{
Ahmed Elmesalamy*, J.A. Francis, L. Li \\ Laser Processing Research Centre, School of Mechanical, Aerospace and Civil Engineering, The University of Manchester, Sackville Street, \\ Manchester M13 9PL, UK
}

\section{A R T I C L E I N F O}

\section{Article history:}

Received 21 May 2013

Received in revised form

19 September 2013

Accepted 13 November 2013

\section{Keywords:}

Cold work

Contour method

Cyclic hardening

Multi pass laser welding

Narrow groove welding

Weld distortion

\begin{abstract}
A B S T R A C T
Thick-section austenitic stainless steels have widespread industrial applications, especially in nuclear power plants. The joining methods used in the nuclear industry are primarily based on arc welding processes. However, it has recently been shown that narrow gap laser welding (NGLW) can weld materials with thicknesses that are well beyond the capabilities of single pass autogenous laser welding. The heat input for NGLW is much lower than for arc welding, as are the expected levels of residual stress and distortion. This paper reports on a preliminary investigation of the through-thickness 2D residual stresses distributions, distortions, and plastic strain characteristics, for the NGLW process using material thicknesses up to $20 \mathrm{~mm}$. The results are compared with those obtained with gas-tungsten arc (GTA) welding. While further work is required on thicker test pieces, preliminary results suggest that the longitudinal tensile residual stresses in NGLW joints are 30-40\% lower than those for GTA welds.
\end{abstract}

(C) 2013 Elsevier Ltd. All rights reserved.

\section{Introduction}

Fusion welding processes generally involve material melting, phase transformations, and multiple thermal cycles. In the welding of thick components, localised heating or cooling cycles can lead to large thermal gradients. The non-uniform expansion and contraction of the material, when coupled with the material constraint in the bulk of a component, introduces misfit strains into the parts being welded. If these misfit strains are modest, they can be accommodated by elastic strains. If, however these misfit strains become too large to be elastically sustained, localised plastic deformation is induced, which leads to the development of residual stresses. Significant residual stresses reside in the vicinity of the weld region after the component has reached thermal equilibrium [1]. This is particularly the case for thick section welds as the number of weld passes can be large, with several heat-up/cooldown thermo-mechanical cycles. Indeed, the accumulated level of plastic deformation and the associated cyclic hardening of the material can be significant.

Residual stresses can play a significant role in accelerating or delaying many failure processes $[2,3]$. Residual stresses in welded

\footnotetext{
* Corresponding author.

E-mail addresses: ahmed4411@yahoo.com (A. Elmesalamy).
}

joints are usually tensile in the fusion zone and heat-affected zone, although compressive stresses can be generated under some circumstances if solid-state phase transformations take place during the welding thermal cycle [4]. Tensile residual stresses are of particular concern because they can contribute to fatigue crack development in a structure even under compressive cyclic loading [5]. They are also considered to be the main reason for the initiation and propagation of stress corrosion cracks (SCC) in austenitic weldments [6]. In addition, the kinetics of defect growth can be affected by residual stresses. Therefore, significant research effort has been directed to understanding the development of residual stresses in power plant welds [4].

The safe operation of a nuclear power plant is highly dependent upon the application of robust structural integrity assessment procedures. The residual stresses arising due to welding operations can be critical in affecting the structural integrity of a power plant. However, there are significant technical challenges associated with measuring residual stresses in thick section welds [7], and without an accurate knowledge of the welding residual stresses, it is likely that conservative or incorrect assumptions will be made, which can ultimately affect the assessment of power plants.

AISI 316L stainless steels are employed frequently in nuclear power plants because they have a high resistance to SCC. However, welding thermo-mechanical cycles have a significant influence on the mechanical properties and on the condition of the material. For example, the development of plastic strain and cold work in the 
vicinity of a welded joint can have a significant influence on the resistance to degradation by SCC in stainless steels [8]. Indeed, time-temperature-sensitization curves generally move toward shorter times with increased levels of cold work [9]. Thus, while the control and minimization of residual stresses at welded joints are critical in designing against failure and improving the lifetime of engineering structures [10], residual stress mitigation techniques such as shot peening, laser shock peening, and low-plasticity burnishing [11] can be difficult to apply to large components, and they will lead to increased cold work at the surface of the material.

Laser welding is an effective, low-distortion joining process, due to the combination of high welding speeds and a low heat input to the welded joint. The development of residual stresses in autogenous laser welds has been investigated previously $[12,13]$. However, multi-pass NGLW can be an efficient process for the welding of thick-section components. Zhang et al. [14], and Starling et al. [15] demonstrated thick section welding using a NGLW approach. Zhang et al. [16] studied the feasibility of applying this technique to the welding of $50 \mathrm{~mm}$ thick stainless steels using an $8 \mathrm{~kW}$ laser. In another study, Salminen et al. studied filler wire interactions with the laser beam in a narrow gap laser welding process [17,18]. Despite NGLW being a very promising technique for thick section welding, detailed through-the-depth residual stress investigations have not been reported in previous studies. Zhang et al. [14], for example, only measured surface residual stresses using the X-ray diffraction technique.

The aim of this work was to investigate the development of through-thickness residual stresses in NGLW of AISI 316L stainless steel, using the contour method. In some cases, surface X-ray diffraction measurements were also carried out on the same specimens for the purpose of validation. In this preliminary study, material thicknesses up to $20 \mathrm{~mm}$ have been investigated, and the results are compared with the residual stresses that were measured in conventional GTA welds for the same thickness. The distortions associated with each technique are also compared, and the cumulative plastic strains arising due to each process have been estimated. It is hoped that this preliminary study will provide an insight to the way in which NGLW affects two of the factors that have a critical influence on the integrity of nuclear welds, namely the development of residual stresses, and the cyclic hardening of the material during multipass welding. It is also hoped that this work will provide a foundation for future work involving welds in thicker sections of material.

\section{Description of welding techniques}

Multi-pass GTA welding and NGLW of $10 \mathrm{~mm}$ thick AISI 316L stainless steel plates was carried out. The welds were $150 \mathrm{~mm}$ long, and after welding the samples measured $150 \mathrm{~mm} \times 200 \mathrm{~mm}$ $\times 10 \mathrm{~mm}$. Fig. 1a shows the joint preparation and a representative weld macrograph for the NGLW. The joint preparation consisted of a $1 \mathrm{~mm}$ root gap with a $1.5 \mathrm{~mm}$ deep root face, and a bevel at an inclination of $3^{\circ}$ on each side. Ten passes were required in order to complete the NGLW with a $1 \mathrm{~kW}$ fibre laser, using a spot diameter of $70 \mu \mathrm{m}$, and with the focal point being located $2 \mathrm{~mm}$ above the upper surface. For the NGLW, an AISI grade 316L stainless steel filler wire with a diameter of $0.8 \mathrm{~mm}$ was used. The welding parameters were based on the results of an optimization process which was reported in a previous study by the authors [19]. In that study, the objective was to eliminate weld defects and to achieve a desirable weld bead profile, but no consideration was given to the influence of the chosen welding parameters on the development of residual stresses. In this work, a laser power of $950 \mathrm{~W}$ was used, together with a welding traverse speed of $590 \mathrm{~mm} / \mathrm{min}$, a wire feed rate of $1.08 \mathrm{~m} / \mathrm{min}$, and a stand-off distance of $8 \mathrm{~mm}$, while using pure argon as the shielding gas.

The joint preparation for the GTA welding, and a macrograph with the track sequences highlighted, are shown in Fig. 1b. The bevel angle for the joint was $30^{\circ}$ on either side. Twelve passes were required to fill the gap. The diameter of the tungsten electrode was $3.2 \mathrm{~mm}$, with a vertex angle of $60^{\circ}$ for the conical tip. The electrode polarity was direct current, electrode negative (DCEN). The filler wire diameter was $2 \mathrm{~mm}$, and the GTA welding parameters are
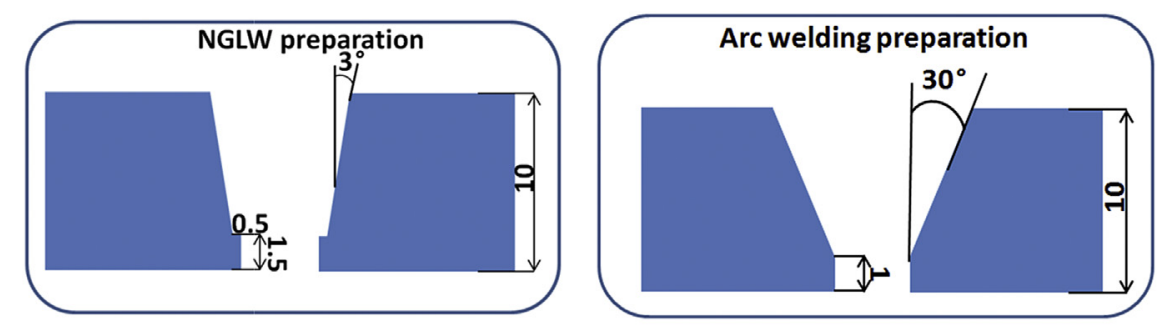

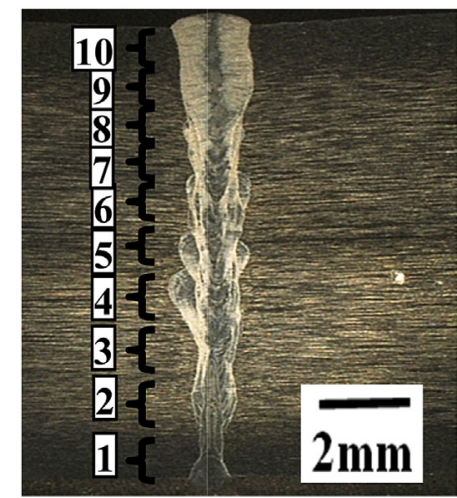

(a)

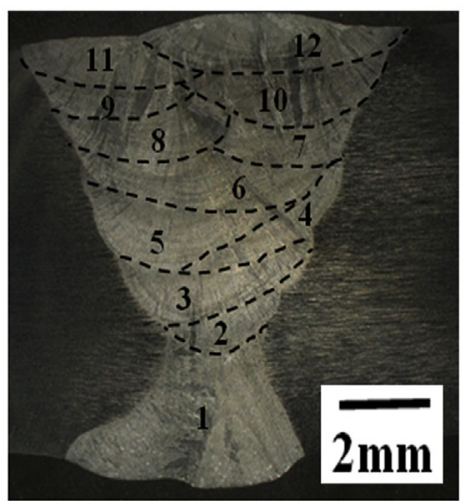

(b)

Fig. 1. Joint preparation and weld bead profiles for $10 \mathrm{~mm}$ thick stainless steel welds using a) NGLW and b) GTA welding. All dimensions in mm. 
shown in Table 1 . The weld width at the upper surface was around $10 \mathrm{~mm}$, while at the lower surface it was approximately $6 \mathrm{~mm}$.

Multi-pass GTA welding and NGLW of $20 \mathrm{~mm}$ thick AISI 316L stainless steel plates was also carried out. The welds were $150 \mathrm{~mm}$ long, and after welding the samples measured $150 \mathrm{~mm} \times 200 \mathrm{~mm} \times 20 \mathrm{~mm}$. Fig. 2 shows the configurations for the welded joints in the $20 \mathrm{~mm}$ thick plates. The welding parameters were nominally identical to those used for the $10 \mathrm{~mm}$ thick plates. The NGLW and GTA welds both followed a two-sided welding sequence. Thirty-four weld passes were required to fill the groove for GTA welding, whereas only 20 passes were required for NGLW. The heat input and number of passes for each welding process and plate thickness are summarised in Table 2.

\section{Residual stress measurement methods}

The contour method was used for the measurement of residual stresses in the welded AISI 316L stainless steel plates manufactured with both the NGLW and the GTA welding techniques. X-ray diffraction was also used to measure residual stresses at the surface, and these measurements served as a check on the residual stress measurements that were made with the contour method.

\subsection{Contour method}

The contour method involves measuring the deformations that occur, due to the relaxation of stresses, when a component is cut in order to evaluate the residual stresses that existed within the component before the cut was made. The method allows one to

Table 1

Summary of GTA welding parameters.

\begin{tabular}{lllll}
\hline Voltage $(\mathrm{V})$ & $\begin{array}{l}\text { Current } \\
(\mathrm{A})\end{array}$ & $\begin{array}{l}\text { Wire feed } \\
(\mathrm{mm} / \mathrm{min})\end{array}$ & $\begin{array}{l}\text { Traverse speed } \\
(\mathrm{mm} / \mathrm{min})\end{array}$ & $\begin{array}{l}\text { Gas flow rate } \\
(\mathrm{l} / \mathrm{min})\end{array}$ \\
\hline 11.5 & 120 & 260 & 130 & 10 \\
\hline
\end{tabular}
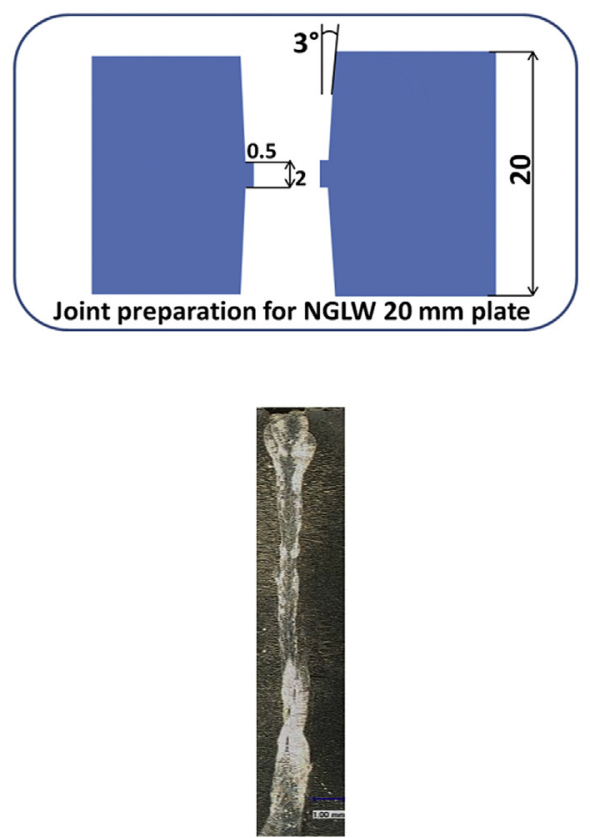

(a)
Table 2

Heat input and number of weld passes for each joint type.

\begin{tabular}{llll}
\hline $\begin{array}{l}\text { Welding } \\
\text { technique }\end{array}$ & $\begin{array}{l}\text { Plate thickness } \\
(\mathrm{mm})\end{array}$ & $\begin{array}{l}\text { Number of } \\
\text { passes }\end{array}$ & $\begin{array}{l}\text { Heat input } \\
\text { per pass [J/mm] }\end{array}$ \\
\hline GTAW (1 side) & 10 & 12 & 305 \\
NGLW (1 side) & 10 & 10 & 42 \\
GTAW (2 sides) & 20 & 34 & 305 \\
NGLW (2 sides $)$ & 20 & 20 & 42 \\
\hline
\end{tabular}

measure the component of residual stress that acts in a direction normal to the plane of the cut, over the expanse of the cut surface i.e. it provides a two-dimensional map of residual stresses. The technique was developed by Prime and it is based on a variant of Bueckner's superposition principles [20,21]. The potential of the contour method was demonstrated on a 12-pass GTA weld, where complex stress variations were captured across the weld crosssection [22]. The results obtained with the contour method were in acceptable quantitative agreement with the outcome of nondestructive measurements based on X-ray diffraction. Many researchers, including Kartal et al. [23], Withers et al. [24] and Edwards et al. [25], have used this technique successfully for the evaluation of the residual stresses in various welds. The technique consists of three main steps. The first step includes cutting the stressed part in a straight path. Electric Discharge Machining (EDM) with skim cutting conditions is believed to be the best processing technique for work piece sectioning [26]. Fig. 3 shows the set-up for the residual stress measurements that were made on the $10 \mathrm{~mm}$ thick plates, and it highlights the three main directions with respect to the work piece: the longitudinal direction (L), the transverse direction $(\mathrm{T})$, and the normal direction $(\mathrm{N})$. Welding was carried out in the longitudinal direction (L), and the cutting occurred in the transverse direction $(\mathrm{T})$.

The second step is scanning the profile (the contour) of the surface in order to quantify the deformation due to the relaxation of stresses. The contours of the surfaces can be measured with a noncontact measuring technique (i.e. laser scanning) or using a
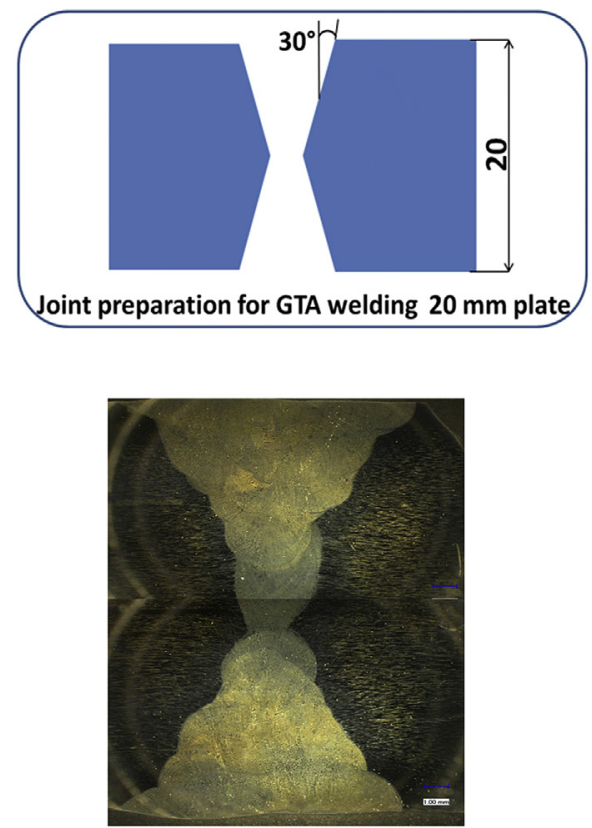

(b)

Fig. 2. Macrographs for $20 \mathrm{~mm}$ thick welds in AISI 316L stainless steel using a) NGLW and b) GTA welding. All dimensions are in mm. 

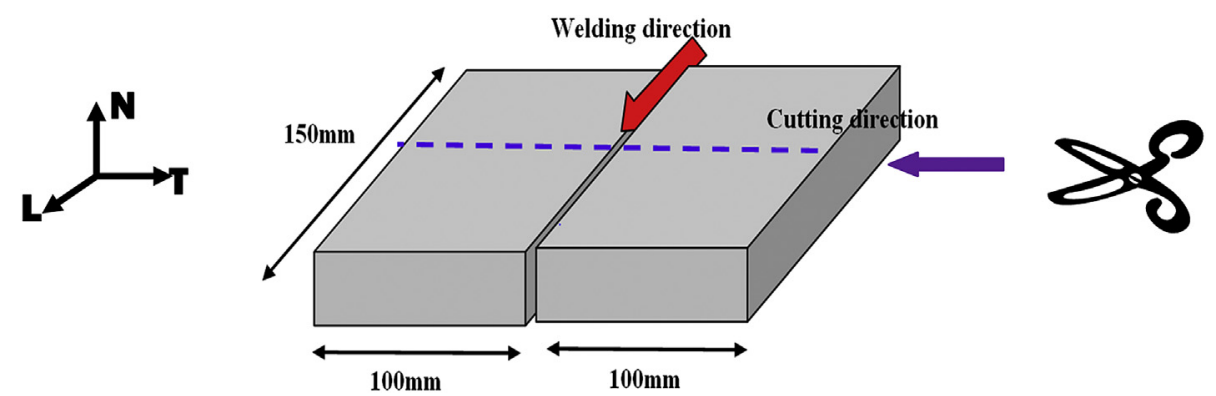

Fig. 3. Welding and cutting directions for the EDM preparation of experimental samples for the contour method measurements.

coordinate measurement machine (CMM) with a touch probe. The final step is data processing, which can be further divided into three sub tasks: data preparation (cleaning up noise, smoothing the scanned surfaces, and averaging the data), calculation of the stresses, and displaying the results.

\subsection{X-ray diffraction $(X R D)$}

X-ray diffraction is a non-destructive technique which can be used to determine the residual stresses at the surface in crystalline materials [27]. The analytical volume for each measurement is restricted to material within a few micrometres of the surface, due to limited beam penetration. The technique allows the changes in the interplanar spacing within the crystal lattice to be determined. Bragg's law is used to determine the interplanar spacing, $d$, at a particular point, corresponding to a scattering angle, $\theta$, and wave length, $\lambda$, by exploiting the relationship in equation (1):

$\lambda / 2=d \sin \theta$

The changes in the interplanar spacing, $d$, can be related to the elastic strain, $\varepsilon$. The strain value is calculated according to the lattice spacing, $d$, and reference spacing $d_{\text {ref }}$ according to equation (2):

$\varepsilon=\frac{d-d_{\text {ref }}}{d_{\text {ref }}}$

The strains in different directions can be calculated in this manner, and the normal stress acting on the free surface can be assumed to be zero. A generalized version of Hooke's law was used to calculate the in-plane components of stress.

\section{Experimental procedures}

\subsection{EDM cutting of specimens}

Specimen cutting is the first and the most critical step when using the contour method, as subsequent procedures are reliant on the quality of the cutting. It is assumed that the cutting process leads to an entirely elastic stress relaxation process, and that cutting does not introduce any stresses to the material. Ideally, the cutting process should be perfectly straight with minimum material removal [28]. All cutting in this work was carried out using a 5axis EDM cutter. The cutting wire was pure copper with a $250 \mu \mathrm{m}$ diameter, following the manufacturer's recommendation for the best cutting results, i.e. minimising the stresses introduced by the cutting operation and the extent of the recast layer.

\subsection{Surface scanning (contour measurement)}

A laser scanner with a non-contact laser head was used for scanning the EDM cut surfaces. The profile of each surface was scanned with an accuracy of $\pm 10 \mu \mathrm{m}$. The scanned profiles showed small deformations due to the relaxation of residual stresses. For example, the dashed line in Fig. 4 represents the edge of the work piece, before distortion due to the welding process. The induced deformation (parallel to the welding direction) is clear in Fig. 4, and some "butterfly" distortion of the specimen is also evident. The contour data for all points on the surface were scanned and saved in the form of $z=f(x, y)$. The scanning was then repeated on the other half of the work piece, before the data were input to a stress analysis module in order to calculate the residual stresses.

\subsection{Data processing}

The raw displacement data for the two halves of the cut were averaged to remove any asymmetric effects associated with wire deviation during cutting, and to compensate for any miss-clamps, and to eliminate the contribution of shear stresses to the measured displacements. The next step was to smooth the data, through creating a least-squares spline curve fit, to eliminate errors associated with cutting stresses, or the measurement conditions, or distortion caused by welding operations. This step is crucial if an accurate evaluation of stresses is to be achieved with the contour method [29]. Fig. 5 shows examples of rough and smoothed scanned surfaces.

Stress analysis is the final step. The smoothed spline surface was input to a finite element (FE) model to create displacement boundary conditions. An arbitrary plane was defined, which represented the initial cut surface, and this was assumed to be perfectly flat. The stress field on the cut surface was calculated as a function of the deformation distance (with the opposite sign), using appropriate material properties for AISI 316L stainless steel. The Young's modulus of the material was assumed to be $193 \mathrm{GPa}$, with a Poisson ratio of 0.3. The FE model was developed using ABAQUS 6.1-CAE.

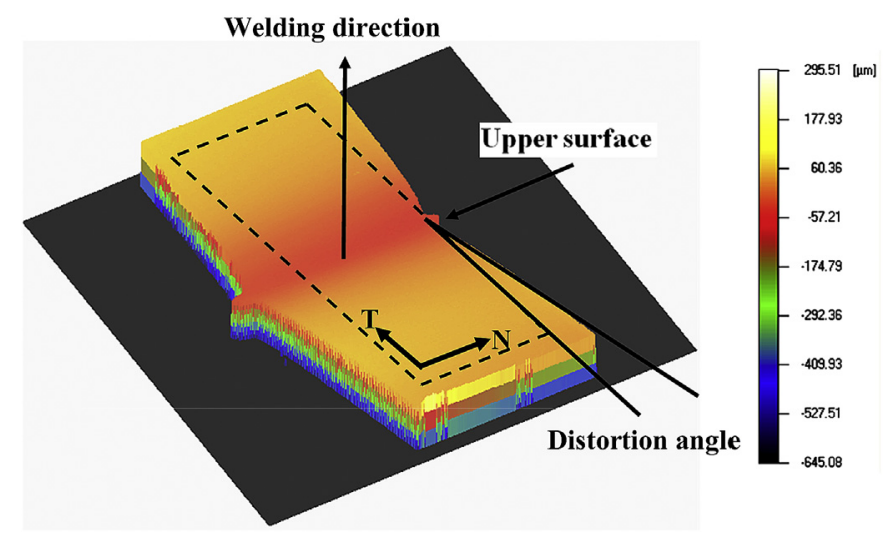

Fig. 4. A scanned surface profile for a GTA weld. 


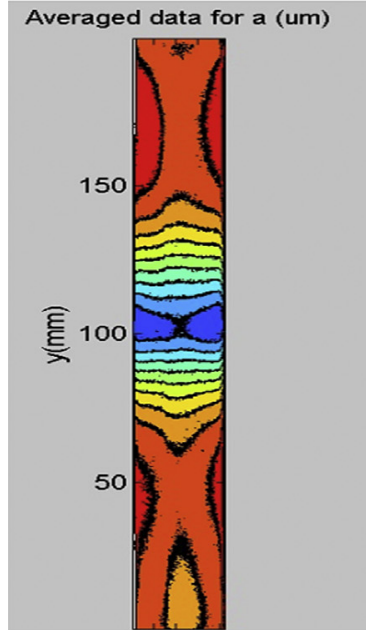

(a)

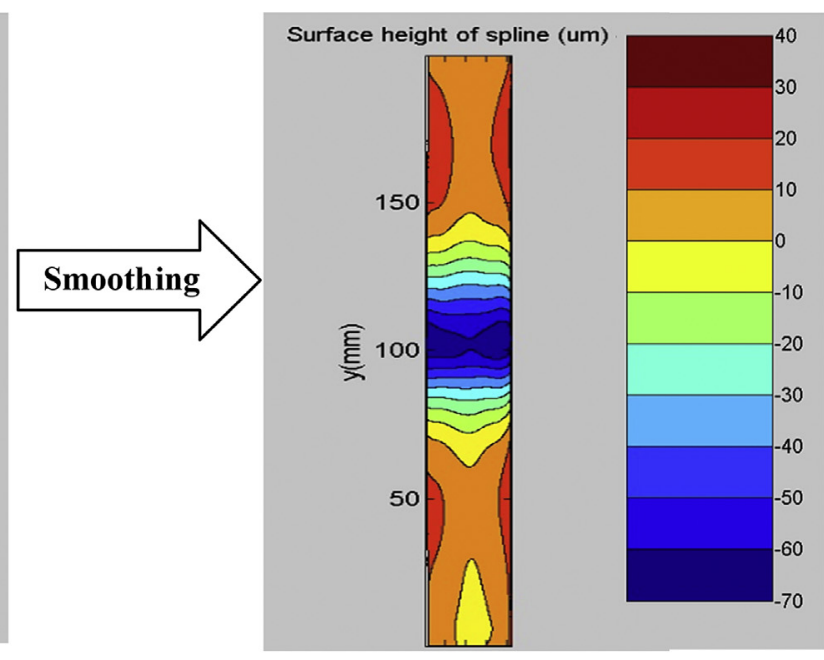

(b)

Fig. 5. Contour maps of (a) rough surface contour (b) smoothed spline fit.

\section{Results and discussion}

The $2 \mathrm{D}$ residual stress profiles through the thickness of the welds were compared in order to understand the influence of the different thermal cycles on the residual stresses induced by each welding technique. The influence of the welding strategy (i.e. onesided or two-sided welding) and the degree of constraint were also investigated.

\subsection{Residual stresses in $10 \mathrm{~mm}$ thick single-sided GTA weld}

Fig. 6 shows the distribution of longitudinal residual stresses for the single-sided GTA weld. The residual stress distribution is approximately symmetrical about the weld centreline. The stresses in the vicinity of the weld centreline are highly tensile, with the peak tensile stress being close to $500 \mathrm{MPa}$ in magnitude. The peak stresses occur at a location that is $2 \mathrm{~mm}$ below the top surface of the weld. The stresses decay gradually with increasing distance from the weld centreline. It is not surprising that the peak tensile stresses occur closer to the upper surface of the specimen, since this is the side of the specimen from which heat was applied during welding. Nine weld passes were required to fill the weld groove, as can be seen in Fig. 1b. The width of the area with a significant tensile (i.e. $>50 \mathrm{MPa}$ ) residual stress is approximately $55 \mathrm{~mm}$ (Fig. 6), and the butterfly distortion angle was $3.9^{\circ}$.

\subsection{Residual stresses in $10 \mathrm{~mm}$ thick NGLW}

Fig. 7 shows the distribution of longitudinal residual stresses for the single-sided NGLW. It can be seen that the residual stresses for the NGLW are lower than those for the single-sided GTA weld. Again, the residual stress distribution is approximately symmetrical about the weld centreline. The stresses in the vicinity of the weld centreline are tensile, but the peak tensile stresses are closer to 300 or $350 \mathrm{MPa}$ in magnitude, and they occur approximately $3 \mathrm{~mm}$ below the upper surface of the specimen on the weld centreline. Four passes were required to fill the lower half of the groove, while six passes were required to fill the upper half, as can be seen in Fig. 1a. The tensile stresses decrease rapidly with distance from the weld centreline, and compressive stresses were measured over significant areas of the measurement plane. There are three reasons for the decrease in the magnitude of residual stresses in the plate joined using NGLW. Firstly, the laser is a high power-density heat source with a very small spot diameter (the spot size was approximately $70 \mu \mathrm{m})$. Secondly, the welding speed $(590 \mathrm{~mm} / \mathrm{min}$ ) was very high compared with that for the GTA weld $(130 \mathrm{~mm} / \mathrm{min})$, and

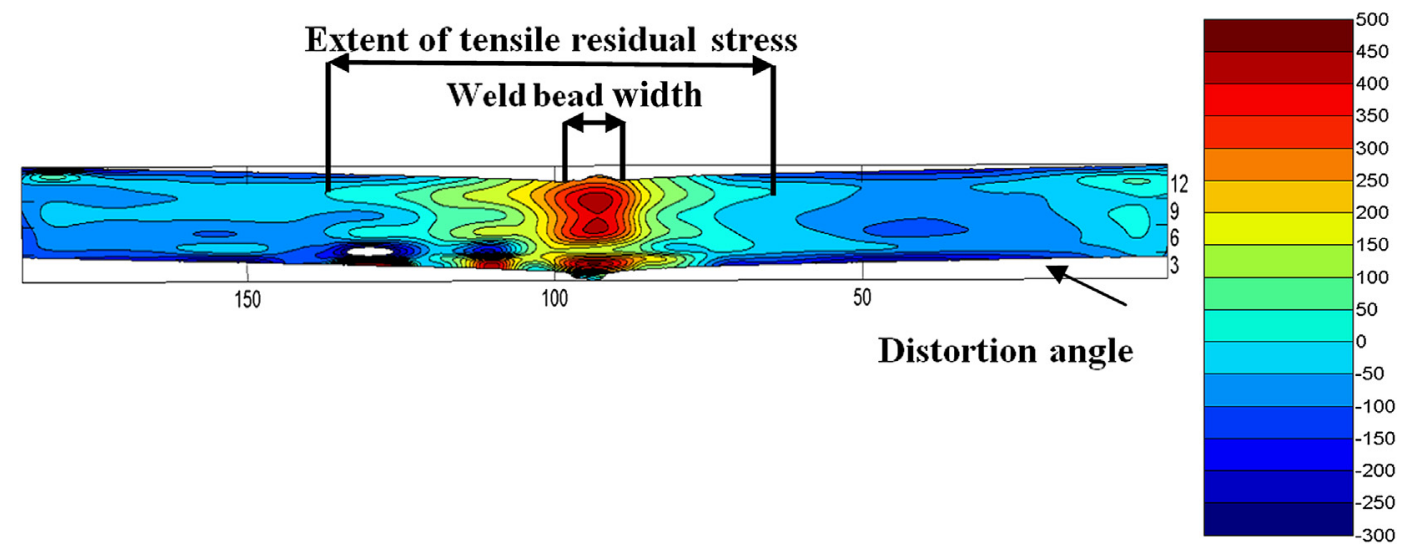

Fig. 6. Residual stress distribution for $10 \mathrm{~mm}$ thick single-sided GTA weld (in MPa). 

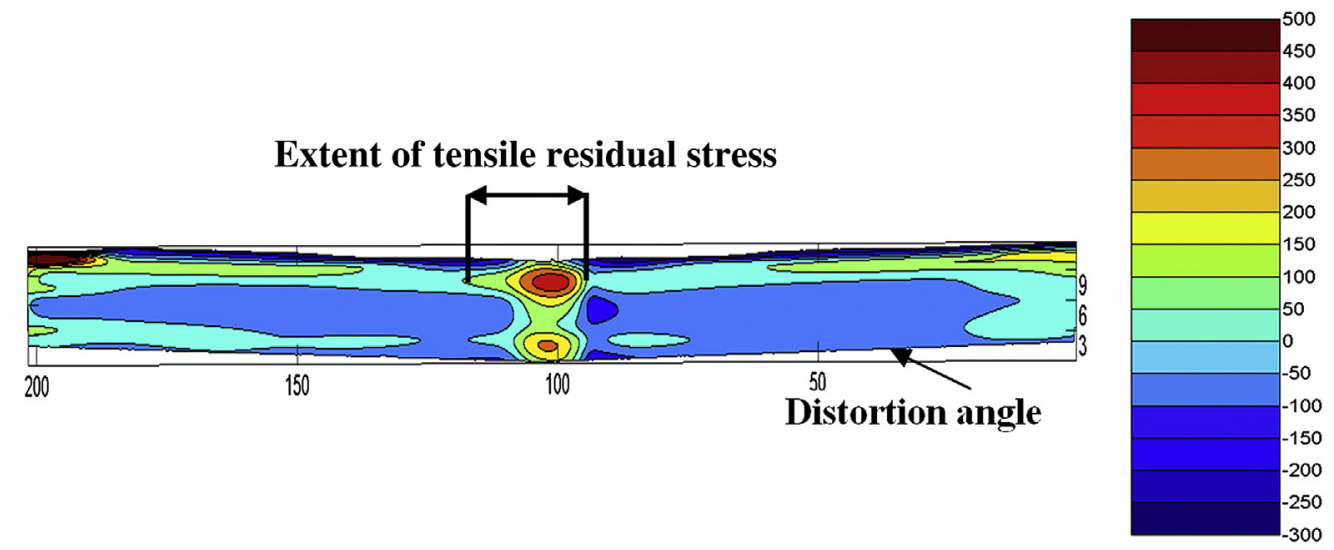

Fig. 7. Residual stress distribution (in MPa) for a single-sided NGLW joint.

finally the width of the weld groove was very small $(\sim 1.25 \mathrm{~mm})$ as can be seen in Fig. 1a. As such, the volume of filler metal required to fill the groove with laser welding is lower than for GTA welding. Consequently, the number of passes and the cumulative heat input to the weld are lower for laser welding than for GTA welding. The width of the region with significant tensile stress ( $>50 \mathrm{MPa}$ ) was approximately $15 \mathrm{~mm}$ for the NGLW, and it decreased towards the upper surface. The magnitude of the stresses was close to zero toward both edges of the specimen, and the butterfly distortion angle was $1.8^{\circ}$. A detailed comparison of the results for each welding process is presented in the next section.

\subsection{Residual stresses near top surface for $10 \mathrm{~mm}$ thick GTA weld and NGLW}

Fig. 8 shows a comparison of the residual stress profiles for the NGLW and the GTA welding processes, measured along a line $1.5 \mathrm{~mm}$ below the upper surface with the contour method. The results suggest that the NGLW technique induces lower residual stresses over the entire width of the specimen. The maximum tensile stress for the NGLW was $310 \mathrm{MPa}$. The tensile stresses for this process decayed sharply with distance from the weld centreline, to a value close to zero, at a distance of approximately $10 \mathrm{~mm}$ from the weld centreline.

The peak tensile residual stress for the GTA weld was $520 \mathrm{MPa}$, and the width of the region with significant tensile stress ( $>50 \mathrm{MPa}$ ) was approximately $50 \mathrm{~mm}$. The tensile stresses at the weld centreline were approximately $40 \%$ lower for the NGLW sample than for the GTAW sample. Fig. 8 shows that the distribution of residual stresses is approximately symmetric about the weld centreline for both processes, with peak stresses occurring at the weld centreline, and with the stresses gradually decreasing until they become compressive further from the weld centreline, which is in agreement with previous studies for GTA welding [3].

\subsection{Residual stress distributions on the weld centreline}

The variations in the residual stress values along the weld centreline, as measured with the contour method, are shown in Fig. 9. The red and blue arrows (in web version) highlight the locations of the measurement lines, and the direction corresponding to an increase in the distance parameter on the horizontal axis, for the GTAW and NGLW samples respectively. There are similar features in the residual stress distributions for each sample. Starting from the lower surface of each sample, the residual stress increases up to an initial peak value, which is approximately $550 \mathrm{MPa}$ for the GTA weld and $250 \mathrm{MPa}$ for the NGLW. With increasing distance from the bottom surface, the stress decreases to approximately $100 \mathrm{MPa}$ for the NGLW, and $150 \mathrm{MPa}$ for the GTA weld, near the mid section. In both samples, the stresses then increase again to the second peak, which is approximately $500 \mathrm{MPa}$ in magnitude for the GTA weld and approximately $400 \mathrm{MPa}$ for the NGLW. Finally, the stresses decrease in both samples towards the top surface, having values of approximately $330 \mathrm{MPa}$ for the GTA weld and $125 \mathrm{MPa}$ for the NGLW. Overall, the average residual stress values are noticeably lower in the NGLW.

\subsection{Surface residual stress measurements with X-ray diffraction}

The residual stress measurements made with the contour method were validated using the X-ray diffraction technique. The

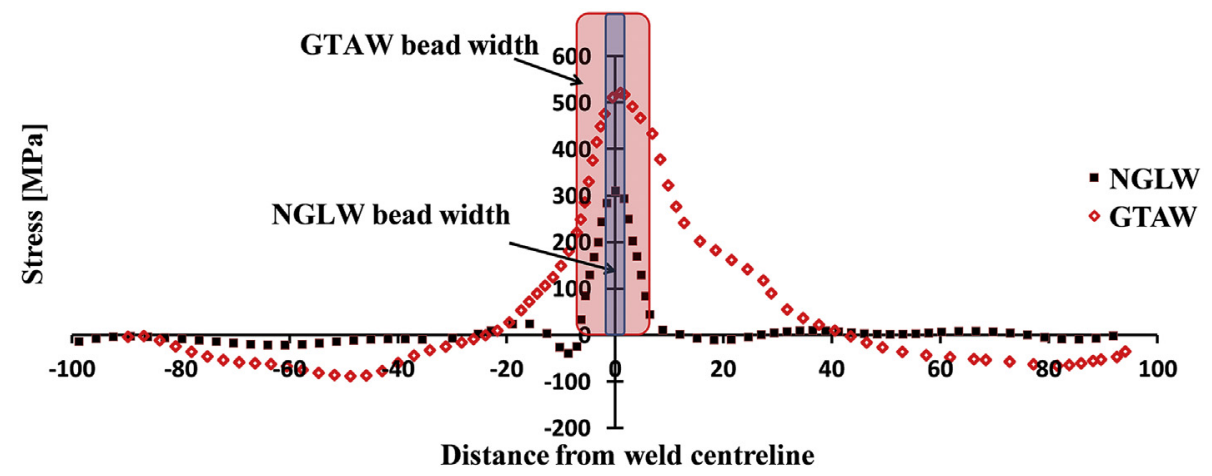

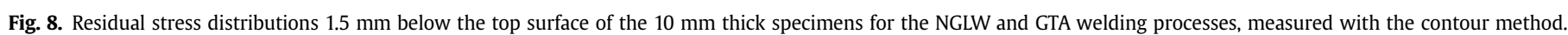




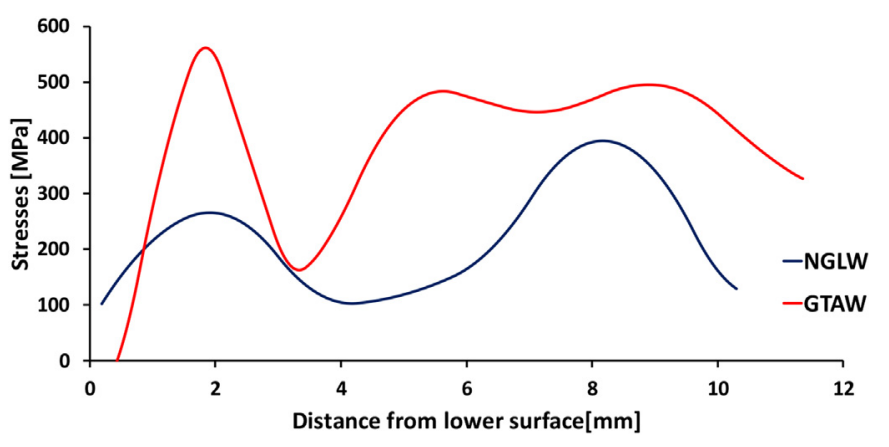

Fig. 9. Variation in residual stresses along the weld centreline for the NGLW and GTAW samples.

longitudinal residual stresses on the upper surface of the NGLW specimen, as measured by the contour method and XRD, are depicted in Fig. 10. The highest value of tensile stress at the upper surface was $190 \mathrm{MPa}$.

Fig. 10 shows that there is good agreement between the stresses measured with the two measurement techniques. It is evident that both techniques capture similar distributions for the longitudinal stresses, with the maximum tensile stresses coinciding with the weld centreline. The stresses quickly become compressive with increasing distance from the weld centreline, and then decay towards the far edges of the specimen. There are small discrepancies in the stress values on the left hand side of the plot. These discrepancies may have arisen, in part, due to the distortion of the welded specimen, which may have affected the accuracy of XRD measurement on this side of the sample. However, the results achieve acceptable agreement across the welded joint.

\subsection{Influence of welding strategy on residual stresses}

The results that have been discussed thus far were all based on welding from a single side. When welding was performed from both sides as shown in Fig. 11, the NGLW technique required 4 passes from each side to fill the gap, with the same parameters that were used for single-sided welding, and the GTAW process required 3 passes from each side to fill the gap. Some features of the doublesided joint preparations were similar to the single-sided weld preparations. The results for the two welding techniques (Fig. 12) show approximately symmetrical residual stress distributions with respect to the weld centreline. The magnitude of the residual stresses is noticeably lower for the NGLW technique. There are two peaks of tensile residual stress on the weld centreline. The peak value for NGLW is 300-350 MPa as shown in Fig. 12a, and the width of the tensile region near each surface is approximately $5 \mathrm{~mm}$. The residual stress distributions for the GTA weld reveal highly tensile peaks with a magnitude of $500 \mathrm{MPa}$ as shown in Fig. 12b. In contrast with the NGLW sample, for GTAW the width of the region with significant tensile stresses is approximately $40 \mathrm{~mm}$.

The two-sided welding strategy resulted in a decrease in the number of passes required to fill the gap. This may have had an influence in reducing the magnitude of the residual stresses for the NGLW, but on the other hand any such effect was insignificant for the GTA welding technique. Finally, it can be seen that using the two sided welding strategy leads to a decrease in the distortion angle to almost zero for both welding techniques.

The influence of the degree of restraint on the nature of the longitudinal residual stresses in the welded joints was investigated. Fig. 13 shows the residual stress distributions for unrestrained NGLW and GTA welds made from one side. These results also show approximately symmetrical residual stress distributions with respect to the weld centreline. The NGLW residual stress distribution is shown in Fig. 13a. The peak residual stress value is between 500 and $550 \mathrm{MPa}$. The butterfly distortion angle is $9.6^{\circ}$. The width of the tensile residual stress region on the weld surface is very narrow at around $10 \mathrm{~mm}$. The GTA welding residual stress distribution is shown in Fig. 13b. The peak residual stress value is also between 500 and $550 \mathrm{MPa}$. The butterfly distortion is far greater at $37.2^{\circ}$. Even though decreasing the level of restraint resulted in an increase in the residual stress magnitudes, especially for the NGLW technique, the NGLW technique still generated significantly smaller tensile regions when compared to GTA welding.

\subsection{Residual stresses in $20 \mathrm{~mm}$ thick samples}

Fig. 14 shows the residual stress maps for the $20 \mathrm{~mm}$ thick samples made with each welding technique. The NGLW technique required 9 passes from each side to fill the prepared gap, while the GTA process required 17 passes from each side to fill the gap. The colour maps show clearly that the stresses for the NGLW technique are lower in magnitude than those for GTA welding. The peak stresses for NGLW are in the range between 300 and $400 \mathrm{MPa}$ (Fig. 14a), while the peak stresses for GTA welding are in the range between 400 and $500 \mathrm{MPa}$ (Fig. 14b). The butterfly distortion is almost zero for each process since the welding followed a two sided welding strategy. The stress maps for each welding technique are similar to the maps corresponding to the two-sided technique for the $10 \mathrm{~mm}$ thick samples. This would suggest that the welding strategy (one-sided versus two-sided) has a more significant effect on the induced residual stresses than the thickness of the sample.

\subsection{Micro-hardness characteristics of $10 \mathrm{~mm}$ thick one-sided welds}

Hardness traverses across the $10 \mathrm{~mm}$ thick NGLW and GTAW specimens were carried out, using a $300 \mathrm{~N}$ load, in order to assess the extent to which the material was work hardened by welding

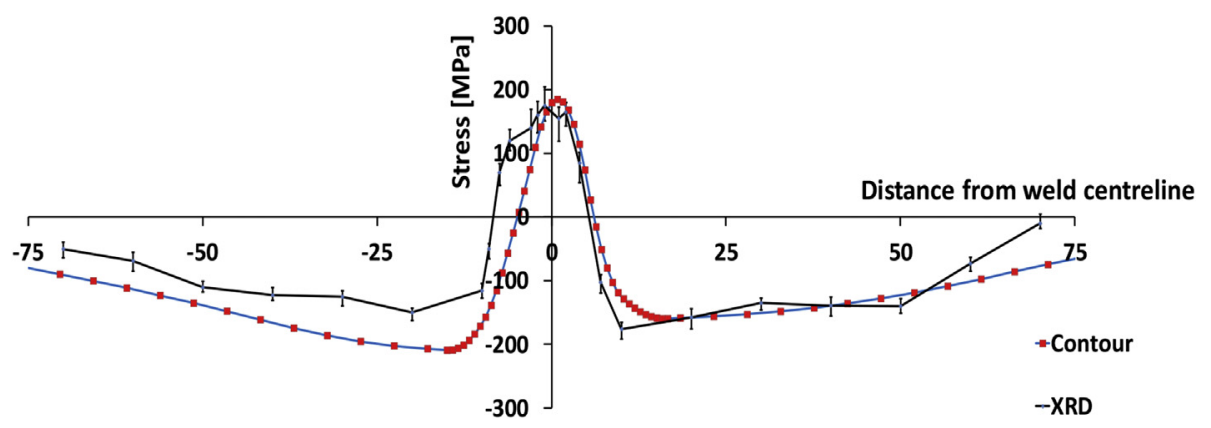

Fig. 10. Comparison of residual stress profiles at top surface of $10 \mathrm{~mm}$ thick NGLW plate, as measured with the contour method and X-ray diffraction. 

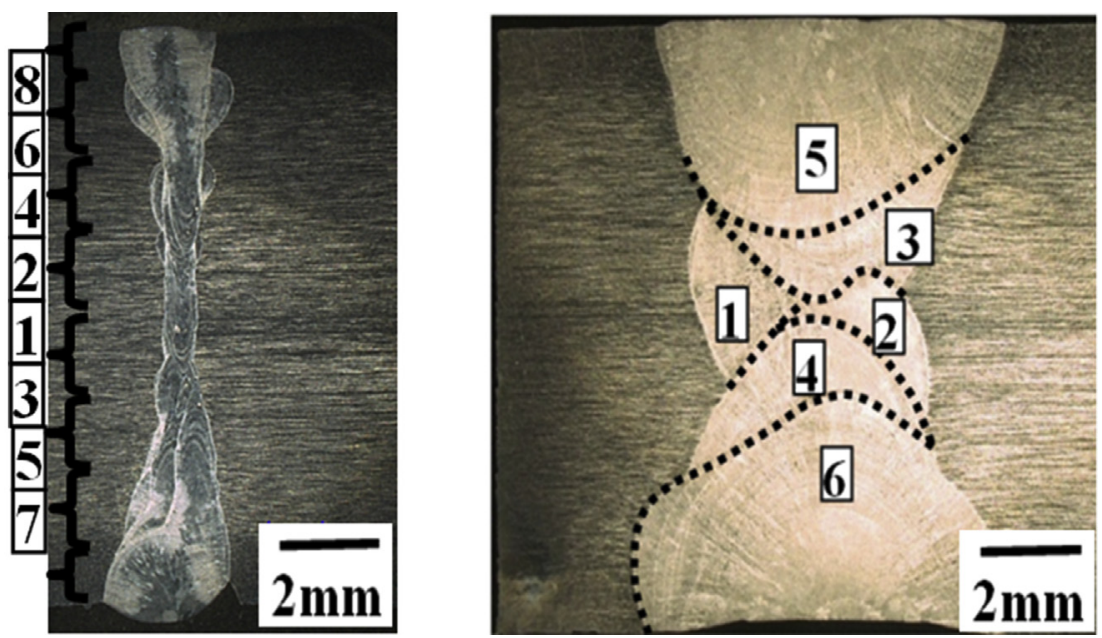

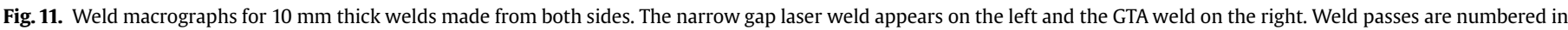
each case.

thermo-mechanical cycles. The location of the measurement line with respect to welded joints is highlighted by a black arrow in Fig. 15. The hardness traverse was located at the mid-thickness position in each sample. The extent to which work hardening occurs can have a significant influence on the tendency of a welded joint to undergo stress corrosion cracking [6]. The hardness distributions across the NGLW and GTAW joints are shown in Fig. 15. The NGLW had a "M" shaped hardness distribution with a peak value of $240 \mathrm{HV}$. The peaks in hardness were located approximately 1-2 $\mathrm{mm}$ from the weld centreline. The hardness then dropped rapidly with increasing distance from the weld centreline to plateau at $160 \mathrm{HV}$ (base material value). The width of hardened material for the NGLW was approximately $15 \mathrm{~mm}$. In contrast, the peak hardness for the GTA weld was $264 \mathrm{HV}$, while the width of hardened material was approximately $80 \mathrm{~mm}$.

\subsection{Micro-hardness characteristics of two-sided welds}

The distribution of hardness was investigated for the two-sided welds (Fig. 16). The results show M-shaped distributions for hardness in all cases (10 and $20 \mathrm{~mm}$ thick samples made with NGLW and GTAW processes). The peak hardness values for the GTA welds in the 10 and $20 \mathrm{~mm}$ thick samples were approximately 255 and 260 HV respectively. The location at which the peak hardness arises is closer to the weld centreline for the $10 \mathrm{~mm}$ thick sample, being approximately $5 \mathrm{~mm}$ away in comparison to an offset of approximately $8 \mathrm{~mm}$ for the $20 \mathrm{~mm}$ thick sample. The peak value of the hardness for the $10 \mathrm{~mm}$ thick NGLW sample is approximately $230 \mathrm{HV}$, while it is approximately $250 \mathrm{HV}$ for the $20 \mathrm{~mm}$ thick NGLW sample. The peak hardness was offset from the centreline by approximately $2 \mathrm{~mm}$ at both thicknesses, as can be seen in Fig. 16 .

\subsection{Estimation of cumulative plastic strains in $10 \mathrm{~mm}$ thick welds}

The thermo-mechanical cycling that occurs during multi-pass NGLW and GTA welding is sufficient to produce plastic strain [8]. This could lead to the rupture of the protective oxide film and, if a crack is initiated, a sustained tensile stress at the crack tip is likely to lead to crack propagation [30]. Plastic deformation has a significant influence on the susceptibility to SCC for "L grade" austenitic stainless steels [8]. Consequently, an investigation into the influence of plastic strain upon the hardness was carried out in order to assist in estimating the cumulative plastic strains across the welded joints. A set of tensile tests was carried out on coupons extracted from the parent material, with the tests being terminated at progressively increasing levels of plastic strain (1\%,3\%, 5\%, 9\%, $15 \%, 30 \%$ and $70 \%$ which corresponds to the point of failure). The hardness values across the samples were recorded. The results reveal a similar trend to that reported by Katayama et al. [8]. Fig. 17 shows the plastic strain - hardness relationship in the stainless steel parent material. Each point on this graph was obtained by taking the average value of hardness, as measured on three separate

a)

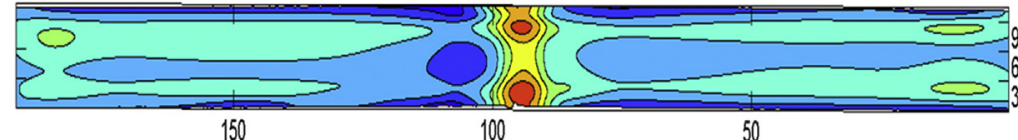

b)
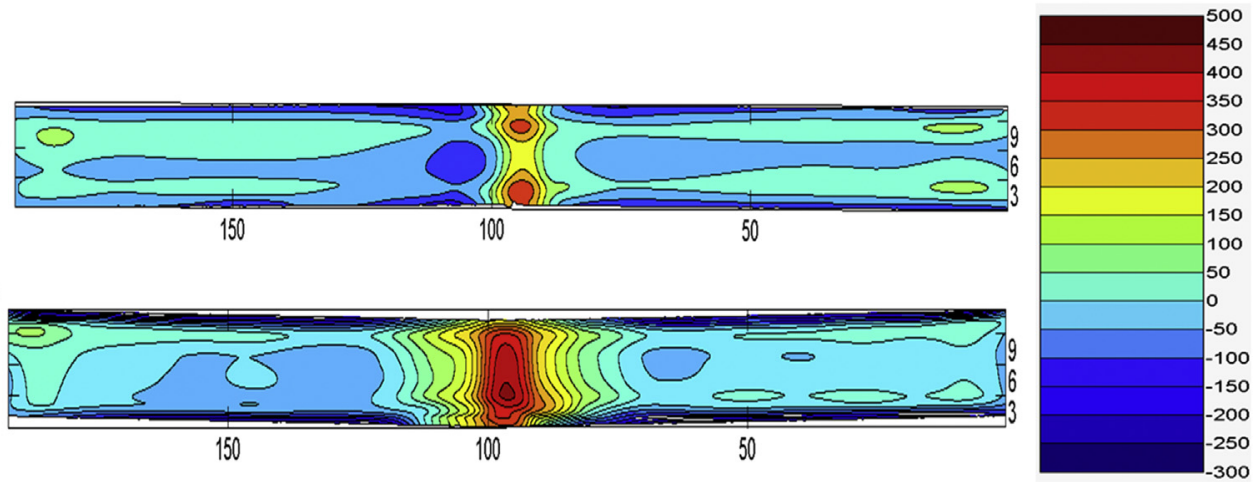

Fig. 12. Residual stress distributions in $10 \mathrm{~mm}$ thick plates for two-sided welding strategy (MPa) a - NGLW b - GTA welding. 
a)
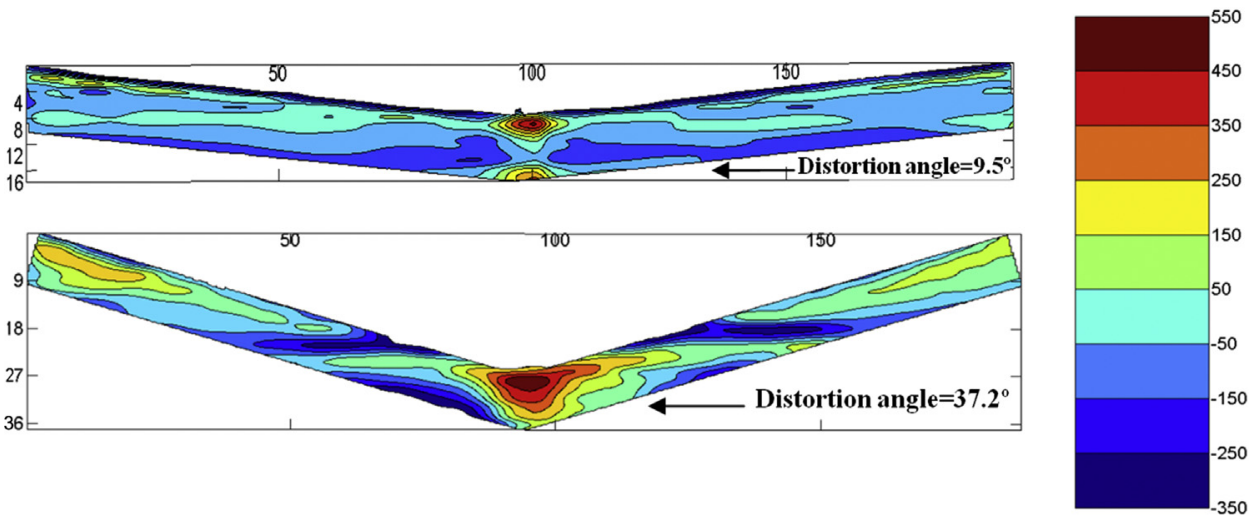

Fig. 13. Residual stress profiles for $10 \mathrm{~mm}$ thick unrestrained welded plates. a) NGLW stress profile b) GTAW stress profile.

(a)

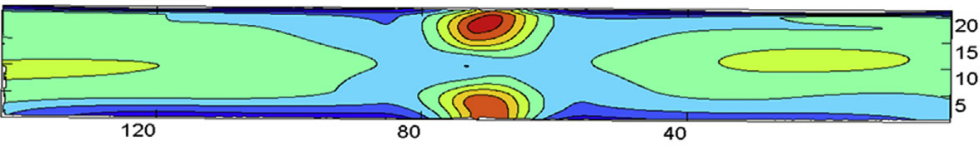

(b)

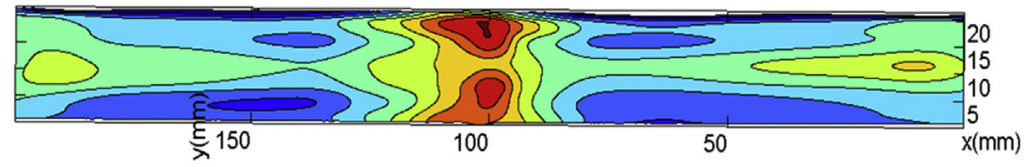

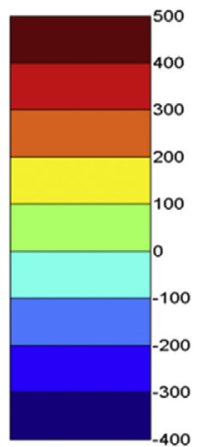

$-400$

Fig. 14. Residual stress profiles for 20 mm thick double-sided welds. a - NGLW stress profile b - GTAW stress profile.

tensile test specimens, for each value of strain. The plotted relationship was then used to relate the hardness that was measured at each point across the welded joint to an estimate for the cumulative plastic strain at that location.

In Fig. 15 we saw that the maximum value across the $10 \mathrm{~mm}$ thick NGLW was $240 \mathrm{HV}$. This value would correspond to an estimated cumulative plastic strain of $13 \%$ according to the data shown in Fig. 17. The maximum value across the $10 \mathrm{~mm}$ thick GTAW sample was $260 \mathrm{HV}$. This value would equate to an estimated cumulative plastic strain of $19 \%$. These results would suggest that the accumulated plastic deformation (or cold work) for the GTA welding process is higher than that in NGLW. It could be inferred, therefore, that the GTA welding technique will produce joints that will be more susceptible to SCC than the NGLW technique. This inference can be drawn from the combination of the higher residual stresses and the higher apparent level of plastic strain in the GTA weld. The doublesided welding strategy was also investigated using the same approach. According to the peak values of hardness shown in Fig. 16, the accumulated values for plastic strain were lower for two-sided welding. For the $10 \mathrm{~mm}$ thick specimens the estimate for the accumulated plastic strain was $11 \%$ for NGLW while it was $17 \%$ for GTA welding. These results suggest that a double-sided welding strategy will lead to lower levels of accumulated plastic strain.

Clearly, there are limitations associated with the above analysis. For example, the plastic strain - hardness relationship in Fig. 17 was established based on the results of uni-axial tension tests, which had been carried out on coupons that were machined from material that was nominally homogeneous. In contrast, welded

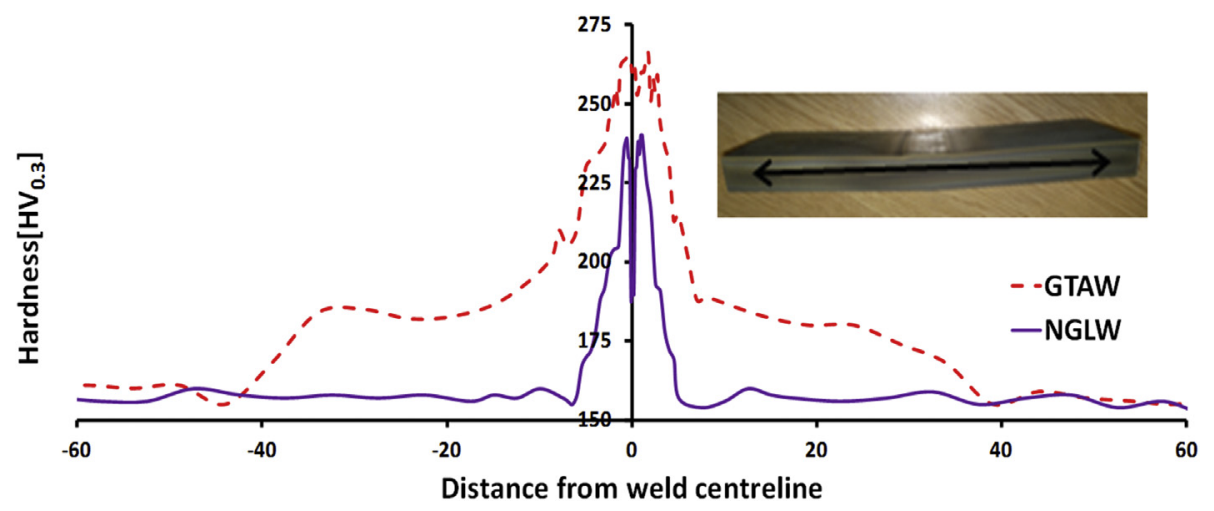

Fig. 15. Hardness distributions for $10 \mathrm{~mm}$ thick single-sided NGLW and GTAW specimens. 


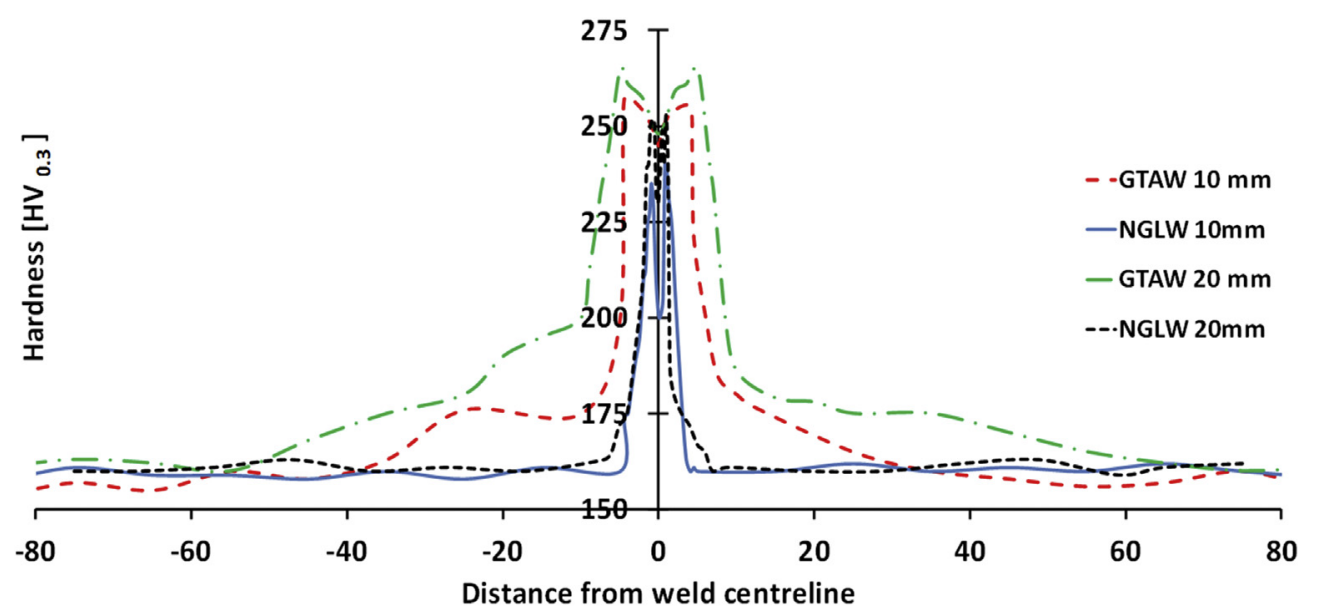

Fig. 16. Hardness distributions for 10 and $20 \mathrm{~mm}$ thick two-sided NGLW and GTAW samples.

joints are heterogeneous and they are often associated with highly tri-axial stress states. Nevertheless, the authors believe that such an analysis provides a useful qualitative comparison of the extent to which plastic strain is induced with each welding technique.

\section{Conclusions}

The following conclusions can be drawn based on the work carried out in this study:

- The results obtained in this study indicate that NGLW may offer significant advantages for the structural integrity of components in cases where tensile residual stresses and accumulated cold work can accelerate material degradation and crack growth.

- The residual stresses were generally 30-40\% lower in magnitude for the narrow gap laser welds in comparison to those for GTA welding. For the restrained $10 \mathrm{~mm}$ thick welds, the peak tensile stress was $\sim 520 \mathrm{MPa}$ for the GTA process and $\sim 310 \mathrm{MPa}$ in the case of NGLW. Furthermore, the NGLW technique resulted in a very narrow tensile stress region close to the upper surface of the welded plates, with the expanse of the tensile stress region being less than $5 \mathrm{~mm}$ to either side of the weld centreline.

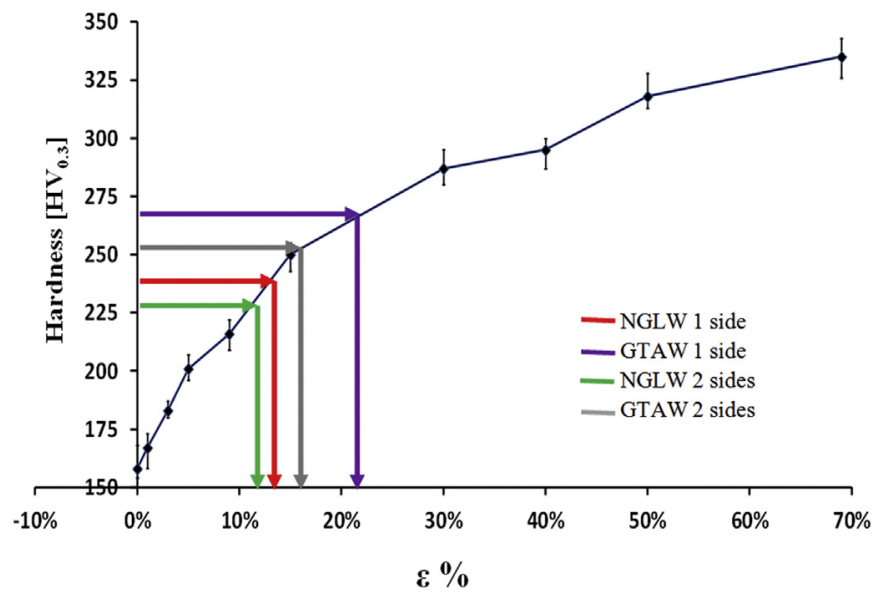

Fig. 17. Variation in Vickers Hardness $\left(\mathrm{HV}_{0.3}\right)$ with homogeneous strain in tensile coupons extracted from AISI grade $316 \mathrm{~L}$ base material. The peak hardness values for the $10 \mathrm{~mm}$ thick single-sided and double-sided NGLW samples, together with the values for the corresponding GTAW samples, are highlighted to give an indication of the accumulated cold work.
- The accumulation of plastic strain due to thermo-mechanical cycling in GTA welding was higher than for NGLW, and a double-sided welding strategy led to lower levels of strain in comparison to a one-sided welding strategy, for both welding processes.

- The butterfly distortion angle for the GTA welds was approximately 3 times higher than for NGLW.

- The welding strategy (single sided welding or double sided welding) had a significant influence on the induced residual stresses, especially for the NGLW technique, while it had a less significant influence for the GTA welding technique.

- The thickness of the welded samples had a less significant influence on the induced residual stresses than the choice of welding process.

\section{Acknowledgements}

-The Egyptian government, Ministry of Defense is gratefully acknowledged for financial support for one of the authors (ASE).

-The research reported in this paper forms part of the UK EPSRC (Engineering and Physics Sciences Research Council) New Nuclear Manufacturing (NNUMAN) programme (EP/J021172/1).

-The authors are grateful to Dr. Philipp Frankel for the provision of technical guidance in relation to the residual stress measurements made with the contour method.

\section{References}

[1] Radaj, D. Heat effects of welding: temperature field, residual stress, distortion, Springer-Verlag; Berlin Heidelberg: 1992.

[2] Withers PJ. Residual stress and its role in failure. Rep Prog Phys 2007:70:2211.

[3] Zhang Y, Pratihar S, Fitzpatrick ME, Edwards L. Residual stress mapping in welds using the contour method. Mater Sci Forum 2005;490:294-9.

[4] Francis JA, Bhadeshia HKDH, Withers PJ. Welding residual stresses in ferritic power plant steels. Mater Sci Technol 2007;23:1009-20.

[5] Cheng X, Fisher JW, Prask HJ, Gnäupel T, Yen BT, Roy S. Residual stress modification by post-weld treatment and its beneficial effect on fatigue strength of welded structures. Int J Fatigue 2003;25:1259-69.

[6] Hornbach DJ, Prevéy PS. The effect of prior cold work on tensile residual stress development in nuclear weldments. J Press Vessel Technol Trans ASME 2002:124:359-65.

[7] Withers PJ, Bhadeshia HKDH. Residual stress. Part 1-measurement techniques. Mater Sci Technol 2001;17:355-65.

[8] Katayama Y, Tsubota M, Saito Y. Effect of the plastic strain level quantified by EBSP method on the stress corrosion cracking of L-grade stainless steels. In: 12th International Conference on Environmental degradation of materials in nuclear power System-Water Reactors, Salt Lake City, Utah, August 14-18, 2005. p. 31-6.

[9] Yoshinori K, Tsubota M, Saito Y. Combination of cold work and heat treatment on stress corrosion cracking susceptibility of L-grade stainless steel. Corrosion 2003:1-13. paper No. 03665. 
[10] Turski M, Bouchard PJ, Smith M, Edwards L, Withers PJ. Spatially resolved materials property data from a cross-weld tensile test. J Press Vessel Technol. Trans ASME 2009;131:1-7.

[11] Zhuang WZ, Halford GR. Investigation of residual stress relaxation under cyclic load. Int J Fatigue 2001;23(Suppl. 1):31-7.

[12] Bang HS, Han SK, You CO, Ik H. A study on mechanical and microstructure characteristics of the STS304L butt joints using hybrid $\mathrm{CO}_{2}$ laser-gas metal arc welding. Mater Design 2011;32:2328-33.

[13] Olabi AG, Benyounis KY, Hashmi MS. Application of response surface methodology in describing the residual stress distribution in $\mathrm{CO}_{2}$ laser welding of AISI304. Strain 2007;43:37-46.

[14] Zhang X, Ashida E, Tarasawa S. Properties of welded joint for narrow gap laser welding of austenitic stainless steels. In: Presented at the Proceeding of 29th. International Congress on Application of Lasers and Electro-Optics (ICALEO), Paper No. 1805, Anhiem, California, USA 2010.

[15] Starling C, Marques PV, Modenesi PJ. Statistical modelling of narrow-gap GTA welding with magnetic arc oscillation. J Mater Process Technol 1995;51:37-49.

[16] Zhang X, Ashida E, Tarasawa S, Ashida E, Tarasawa S, Anma Y, et al. Welding of thick stainless steel plates up to $50 \mathrm{~mm}$ with high brightness lasers. J Laser Appl 2011;23:022002.

[17] Salminen AS. Effects of filler wire feed on the efficiency of laser welding; 2003. pp. 263-8.

[18] Salminen A. The filler wire-laser beam interaction during laser welding with low alloyed steel filler wire. Mechanika 2010;4:67-74.

[19] Elmesalamy AS, Li L, Francis JA, Sezer HK. Understanding the process parameter interactions in multiple-pass ultra-narrow-gap laser welding of thick-section stainless steels. Int J Adv Manuf Technol 2013;68(1-4):1-17.

[20] Prime MB. Cross-sectional mapping of residual stresses by measuring the surface contour after a cut. Trans AMSE J Eng Mater Technol 2001;123:162-8.
[21] Pagliaro P, Prime MB, Swenson H, Zuccarello B. Measuring multiple residualstress components using the contour method and multiple cuts. Exp Mech 2010;50:187-94.

[22] Prime MB, Hughes DJ, Webster PJ. Weld application of a new method for cross-sectional residual stress mapping. In: Proceedings of 2001 SEM Annual Conference on Experimental and Applied Mechanics (Portland, OR) 2001. pp. 608-11.

[23] Kartal ME, Liljedahl CM, Gungor S, Edwards L, Fitzpatrick ME. Determination of the profile of the complete residual stress tensor in a VPPA weld using the multi-axial contour method. Acta Materialia 2008;56:4417-28.

[24] Withers PJ, Turski M, Edwards L, Bouchard PJ, Buttle DJ. Recent advances in residual stress measurement. Int J Press Vessel Pip 2008;85:118-27.

[25] Edwards L, Smith MC, Turski M, Fitzpatrick ME, Bouchard PJ. Advances in residual stress modeling and measurement for the structural integrity assessment of welded thermal power plant. Adv Mater Res 2008;41:391400.

[26] Prime MB. Cross-sectional mapping of residual stresses by measuring the surface contour after a cut. Trans Am Soc Mech Eng J Eng Mater Technol $2001 ; 123: 162-8$

[27] Casavola C, Pappalettere C, Tursi F. Residual stress on Ti6Al4V hybrid and laser welded joints. Eng Appl Residual Stress 2011;8:111-8.

[28] Turski M, Edwards L. Residual stress measurement of a 3161 stainless steel bead-on-plate specimen utilising the contour method. Int J Press Vessel Pip 2009;86:126-31.

[29] Zhang Y, Ganguly S, Edwards L, Fitzpatrick ME. Cross-sectional mapping of residual stresses in a VPPA weld using the contour method. J Acta materialia 2004;52:5225-32.

[30] Weeks JR, Vyas B, Isaacs HS. Environmental factors influencing stress corrosion cracking in boiling water reactors. Corros Sci 1985;25:757-68. 